$\xi=-1$

\title{
Parametric optimization of Edm on Hastelloy C-276 Using Taguchi L18 Technique
}

\author{
Sk.Khadar Basha ${ }^{1}$, Murahari Kolli2 ${ }^{2}$, M.V.Jagannadha Raju ${ }^{3}$ \\ ${ }^{1}$ Department of mechanical engineering, Koneru Lakshmaiah Education Foundation, Vaddeswaram, \\ Guntur, Andhra Pradesh, India - 522502 \\ ${ }^{2}$ Department of Mechanical Engineering, Lakkireddy Balireddy College of engineering, Mylavaram, Andhra Pradesh, India-521230 \\ ${ }^{1,3}$ Department of mechanical engineering, Andhra University, Visakhapatnam, Andhra Pradesh, India-530003 \\ *Email: kmhari.nitw@gmail.com
}

\begin{abstract}
Due to development in machining science the use of composites and alloys is a great deal for every industry. Hastelloy C276 the most versatile corrosion resistant nickel based super alloy which is used for industrial applications is considered for doing the experiments.The high nickel and molybdenum content provides better corrosion resistance at extreme environments. In this report, the experiments are performed by using Taguchi L18 technique and their results are used for performance of each process parameters on their output responses. The process parameters considered for experimentation are discharge current, pulse- on- time, type of electrode and pulse off time for the output responses of material removal rate and surface roughness. Eco-friendly (drinking water) is used as a dielectric fluid. The experiments are designed and conducted using Taguchi L18 technique and analyze the influence of each process parameters on machining performance characteristics. Further, mathematical equations were developed using the statistical software MINITAB17.0.ANOVA is used for analyzing the experimental results obtained. It was observed from the response table that the average values of MRR and SR for pulse on time, discharge current, electrode are identified as important process parameters.
\end{abstract}

Keywords: Hastelloy C-276, Taguchi L18, Eco friendly dielectric, EDM

\section{Introduction}

In the past two decades advanced machining process are widely used in engineering and industrial fields. it is essential to machine hard, composite, ceramics and complex materials without varying their surface topography in the aspects of manufacturing. A nickel based super alloy Hastelloy C-276 with $30 \%$ of chromium and molybdenum weight makes the alloy more corrosive resistant. In this research an advanced machining process EDM is used for machining of hastelloy C-276[1].In EDM process the material removal is based on an interrupted electric spark discharges among the electrode (cathode) and the Material (anode) which was submerged in dielectric fluid. Due to high temperature of spark in the machining zone the material is removed from the work piece due to high temperature of spark in the machining zone. The thermoelectric energy is formed between work piece and an electrode submerged in dielectric fluid with a transmission of electric current[2].

In this paper, HASTELLOY®C-276 alloy was used for performing the experiments with Die sinking EDM machine. This alloy is a registered trademark of special metal family of industries. Additionally, this alloy can be used in application like AP1000 reactor coolant pump, agitator blades and turbine blades [3-4].

Ahmed et al [5] attempted a modification of surface of hastelloy using the particles of Sic by Electron Beam Melting (EBM).They concluded that when Sic particles added in to EBM process, particles are broken into small pieces and spared in the material surface that effect increasing the surface hardness of the material. Karim baig and venkaiah [6] optimized Wire cut EDM process parameters of Hastelloy using Grey Taguchi technique. They observed that optimal parameters setting for maximum MRR is obtained at higher levels of parameters, minimum Kerf and SR is obtained at lower level of parameters.

It was identified from the literature that a limited work has been done on EDM of HASTELLOY C-276 using the dielectric which is an eco-friendly. Taguchi L18 technique is used for optimizing the machining parameters. The ANOVA results identified the best process parameters and also developed the mathematical equations on selected performance characteristics.

\section{Experimental Setup}

The EDM model 50 Die sinking machine is used for conducting the experiments. The size of the work piece considered for doing the experimentation is $50 \mathrm{~mm}$ length and width having $5 \mathrm{~mm}$ thickness. The electrode used for the experimental study is graphite with $16 \mathrm{~mm}$ diameter and $70 \mathrm{~mm}$.

The work piece and electrode are cleaned and polished using emery papers before conducting experiments. An eco-friendly dielectric is used as a dielectric fluid which reduces the pollution and cost of experimentation.

Each experiment is conducted for duration of 5 minutes. Electronically digital weighing balance is used for measuring the mass of the electrode and material before and after every experimentation.SR is measured with the handy surf instrument on the machined surface at different directions. The average of six readings is taken on the machine hole for effective value of 
SR.The working conditions of the EDM machine is given in the table 1. The control parameters are considered according to number of trials conducted and on operator experience [10] .

Process parameters used for experimentation work are type of electrode, discharge current, pulse on time and pulse off time. The levels and range of process parameters are shown in the table 2 .

Table1: Experimental procedure

\begin{tabular}{|l|l|}
\hline Working parameters & Description \\
\hline Workpiece materials & HASTELLOY C-276 \\
\hline Size of work piece & $50 * 50 * 5$ \\
\hline Electrode material and Size & Copper,Graphite $(\Phi 14 \mathrm{~mm} * 70 \mathrm{~mm})$ \\
\hline Polarity of Electrode & Positive \\
\hline Dielectric & Drinking water \\
\hline Discharge voltage & $110 \mathrm{~V}$ \\
\hline Discharge gap & $65 \mathrm{~V}$ \\
\hline Flushing pressure & $0.75 \mathrm{Mpa}$ \\
\hline Time required for machining & $5 \mathrm{~min}$ \\
\hline
\end{tabular}

\section{Planning of Experiments using Taguchis method}

Taguchi method is the most appropriate problem solving tool, which is used to improve the product and process design and to analyze the effects of machining parameters on performance measures at optimal conditions.

The main variation between standard design of experiments and Taguchi's orthogonal array design of experiments is that the former focuses only on the mean of the response whereas later focuses mainly on the minimization of variation of the response of interest. Further the method significantly reduces the experiments to be conducted for optimization and saves experimentation cost, energy and time period. Taguchi L18 technique is used to analyze the influence of each process parameters on machining performance characteristics. The deviations of response for the mean values are calculated using SNR [7-9]. The quality characteristics are represented in equation 1 and 2 .

$$
\begin{aligned}
& \eta=-10 \log _{10}\left[\frac{1}{n} \sum_{i=1}^{n} \frac{1}{y_{i}^{2}}\right] \\
& \eta=-10 \log _{10}\left[\frac{1}{n} \sum_{i=1}^{n} y_{i}^{2}\right]
\end{aligned}
$$

In this investigation, the Taguchi's method was used to plan, Design and conducting the experiments using MINITAB 17 software. The MRR and SR values calculated for each levels keeping the parameters constant are shown in table III .From the above equation the $\mathrm{S} / \mathrm{N}$ ratio values are calculated to obtain the machining performance of different experiments conducted.

The response graphs are shown in figure 1 and 2.The $\mathrm{S} / \mathrm{N}$ ratio with higher value gives the better performance which is considered as a optimum level parameter.

Table 2: Control parameters

\begin{tabular}{|c|c|c|c|c|c|}
\hline Symbols & $\begin{array}{c}\text { Control fac- } \\
\text { tors }\end{array}$ & \multicolumn{2}{|l|}{ Levels } & Units \\
\hline $\mathrm{A}$ & Electrode & $\mathrm{Cu}$ & $\mathrm{Gr}$ & & \\
\hline $\mathrm{B}$ & $\begin{array}{c}\text { Discharge } \\
\text { current }\end{array}$ & 8 & 12 & 16 & $\mathrm{Amp}$ \\
\hline $\mathrm{C}$ & $\mathrm{T}_{\text {on }}$ & 25 & 45 & 65 & $\mu \mathrm{s}$ \\
\hline $\mathrm{D}$ & $\mathrm{T}_{\text {off }}$ & 20 & 32 & 44 & $\mu \mathrm{s}$ \\
\hline
\end{tabular}

\begin{tabular}{|c|c|c|c|c|c|c|}
\hline $\mathbf{E x}$ & $\mathbf{A}$ & B & $\mathrm{C}$ & D & $* \operatorname{MRR}\left(\mathrm{mm}^{3} / \mathrm{m}\right.$ & $* \mathrm{SR}(\mu \mathrm{m})$ \\
\hline 1 & $\mathrm{Cu}$ & 8 & 25 & 20 & 7.609 & 2.78 \\
\hline 2 & $\mathrm{Cu}$ & 8 & 45 & 32 & 9.888 & 2.86 \\
\hline 3 & $\mathrm{Cu}$ & 8 & 65 & 44 & 10.608 & 3.35 \\
\hline 4 & $\mathrm{Cu}$ & 12 & 25 & 20 & 11.991 & 3.23 \\
\hline 5 & $\mathrm{Cu}$ & 12 & 45 & 32 & 13.874 & 3.54 \\
\hline 6 & $\mathrm{Cu}$ & 12 & 65 & 44 & 14.512 & 3.90 \\
\hline 7 & $\mathrm{Cu}$ & 16 & 25 & 32 & 15.890 & 3.87 \\
\hline 8 & $\mathrm{Cu}$ & 16 & 45 & 44 & 16.718 & 4.26 \\
\hline 9 & $\mathrm{Cu}$ & 16 & 65 & 20 & 18.744 & 5.24 \\
\hline 10 & $\mathrm{Gr}$ & 8 & 25 & 44 & 25.639 & 3.21 \\
\hline 11 & Gr & 8 & 45 & 20 & 30.116 & 3.82 \\
\hline 12 & $\mathrm{Gr}$ & 8 & 65 & 32 & 34.706 & 4.20 \\
\hline 13 & $\mathrm{Gr}$ & 12 & 25 & 32 & 28.017 & 3.82 \\
\hline 14 & $\mathrm{Gr}$ & 12 & 45 & 44 & 31.132 & 4.04 \\
\hline 15 & Gr & 12 & 65 & 20 & 29.940 & 5.46 \\
\hline 16 & $\mathrm{Gr}$ & 16 & 25 & 44 & 34.184 & 4.27 \\
\hline 17 & $\mathrm{Gr}$ & 16 & 45 & 20 & 29.91 & 5.47 \\
\hline 18 & Gr & 16 & 65 & 32 & 37.218 & 6.16 \\
\hline
\end{tabular}

Table 3: Average results of MRR and SR

Table 4: Results of MRR and SR with S/N ratio.

\begin{tabular}{|c|c|c|c|r|}
\multicolumn{7}{|c}{ Table 4: Results of MRR and SR with S/N ratio. } \\
\hline Ex No & *MRR & S/N Ratio & $*$ SR & S/N Ratio \\
\hline 1 & 7.609 & 17.6260 & 2.78 & -8.8809 \\
\hline 2 & 9.888 & 19.9018 & 2.86 & -9.27786 \\
\hline 3 & 10.608 & 20.5131 & 3.35 & -9.85521 \\
\hline 4 & 11.991 & 21.5771 & 3.23 & -10.1841 \\
\hline 5 & 13.874 & 22.8442 & 3.54 & -10.9801 \\
\hline 6 & 14.512 & 23.2344 & 3.90 & -11.8213 \\
\hline 7 & 15.890 & 24.0225 & 3.87 & -11.7542 \\
\hline 8 & 16.718 & 24.4637 & 4.26 & -13.0449 \\
\hline 9 & 18.744 & 25.4572 & 5.24 & -15.0102 \\
\hline 10 & 25.639 & 28.1781 & 3.21 & -11.5957 \\
\hline 11 & 30.116 & 29.5760 & 3.82 & -11.6413 \\
\hline 12 & 34.706 & 30.8080 & 4.20 & -12.465 \\
\hline 13 & 28.017 & 28.9484 & 3.82 & -11.6413 \\
\hline 14 & 31.132 & 29.8641 & 4.04 & -12.1276 \\
\hline 15 & 29.940 & 29.5250 & 5.46 & -14.7439 \\
\hline 16 & 34.184 & 30.6766 & 4.27 & -12.6086 \\
\hline 17 & 29.913 & 29.5172 & 5.47 & -14.7597 \\
\hline 18 & 37.218 & 31.4150 & 6.16 & -15.7916 \\
\hline
\end{tabular}

\section{Results and Discussions}

The impact of process parameters on the EDM of Hastelloy C-276 is analyzed using parametric optimization. The $\mathrm{S} / \mathrm{N}$ ratio values for each experiment is calculated and shown in the table III and IV

\section{A.ANOVA analysis for MRR}

The graph of MRR is displayed in the figure 1.The Figure indicates that as current increases from 8amp to 16amps the MRR gradually increases.

Table 5 shows the ANOVA results for each parameter identified.The model $F$ value of 1334.71 with prob> value less than 0.0001 indicates that the model terms are significant for MRR.In this $A, B, C$ and $D$ are significant model terms. The value of $R^{2}$ and $\mathrm{R}^{2}$ (adj) are $98.58 \%, 97.59 \%$ respectively.

Table 5 : ANOVA results for MRR

\begin{tabular}{|l|l|l|l|l|l|l|}
\multicolumn{7}{|c}{ Table 5 : ANOVA results for MRR } \\
\hline Source & DF & Seq SS & $\begin{array}{l}\text { Adj } \\
\text { MS }\end{array}$ & F & P & $\%$ \\
\hline A & 1 & 1445.30 & 722.65 & 1334.71 & 0.000 & $\begin{array}{l}88.6 \\
6\end{array}$ \\
\hline B & 2 & 126.18 & 63.09 & 58.26 & 0.000 & 7.74 \\
\hline C & 2 & 40.01 & 20.00 & 18.47 & 0.000 & 2.45 \\
\hline D & 2 & 7.90 & 3.45 & 3.65 & 0.005 & 0.50 \\
\hline $\begin{array}{l}\text { Residual } \\
\text { ror }\end{array}$ & 10 & 10.83 & 5.41 & & & 0.64 \\
\hline \begin{tabular}{l} 
Total \\
\hline
\end{tabular} & 17 & 1630.21 & & & & $\begin{array}{l}100 . \\
00\end{array}$ \\
\hline
\end{tabular}




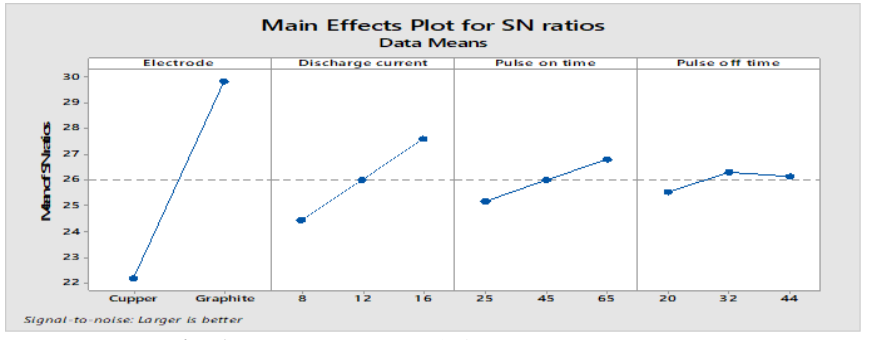

Fig. 1:S/N response graph for MRR

$\mathrm{S}=1.5132$, R-sq $98.58 \%$, R-sq(adj) $97.59 \%$, R-sq(prd) $-95.40 \%$ MRR empirical equation $=22.276-8.91 * \mathrm{Cu}+8.961 \mathrm{Gr}-3.091 * \mathrm{~A} 1-$ $0.284 * \mathrm{~A} 2+3.375 * \mathrm{~A} 3-1.691 * \mathrm{~B} 1$

$0.245 * \mathrm{~B} 2+0.6361 * \mathrm{~B} 3+0.334 * \mathrm{C} 1+0.925 * \mathrm{C} 2-0.591 * \mathrm{C} 3$.

From the figure it was identified that the MRR increases with increase in pulse on time. At pulse off time there is no removal of material from the work piece due to the lack of power in the machining area. During pulse off time the MRR increases up to 32 and beyond that it decreases.

The optimum conditions for each process parameter are shown in the figure.

\section{B.ANOVA analysis for SR}

The analysis of variance for SR is shown in Table VI. It depicts that Discharge current was considered as an important factor with a contribution of $45.06 \%$ and electrode, pulse on time, pulse off time with a contribution of $20.00 \%, 28.13 \%, 4.81 \%$ respectively.

It was observed that current has prominent impact on SR.The figure shows that surface roughness increases with increase in discharge current. The increase in discharge current results in increase of higher spark energy forming the expansive and bigger pits[11].

Table 6: ANOVA results for SR

\begin{tabular}{|c|c|c|c|c|c|c|}
\hline Source & DF & Seq SS & $\begin{array}{c}\text { Adj } \\
\text { MS }\end{array}$ & F & P & $\%$ \\
\hline A & 1 & 3.058 & 1.529 & 100.49 & 0.000 & 20.00 \\
\hline B & 2 & 6.888 & 3.444 & 113.15 & 0.000 & 45.06 \\
\hline C & 2 & 4.299 & 2.149 & 70.63 & 0.000 & 28.13 \\
\hline D & 2 & 0.735 & 0.367 & 12.08 & 0.002 & 04.81 \\
\hline $\begin{array}{c}\text { Residual } \\
\text { error }\end{array}$ & 10 & 0.304 & 0.152 & & & 02.00 \\
\hline Total & 17 & 15.286 & & & & 100.0 \\
\hline
\end{tabular}

\section{$S=0.17445$, R-sq 98.01\%, R-sq(adj) 96.62\%, R-sq(prd) -93.55}

Empirical equation of $\mathrm{SR}=4.0822-0.4122 * \mathrm{Cu}-0.7122 * \mathrm{~A} 1-$ $0.0839 * \mathrm{~A} 2+0.7961 * \mathrm{~A} 3-0.5522 * \mathrm{~B} 1-$

$0.0839 * \mathrm{~B} 2+0.6361 * \mathrm{~B} 3+0.25 * \mathrm{C} 1-0.0072 * \mathrm{C} 2-0.2439 * \mathrm{C} 3$.

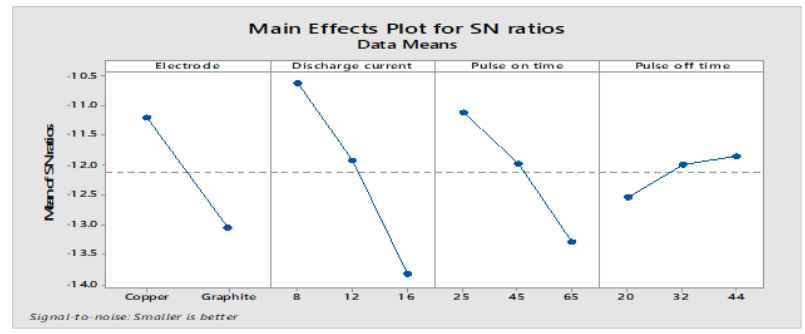

Fig .2: S/N response graph for SR

During pulse on time the heat energy melts the work piece in the time period.This energy splits into huge number of sparks which decrease the crater size results in increase of surface finish [12]. The impact and consequence of pulse on time is greater for SR. The conditions are maximum at Discharge current 16 amps,pulse on time $65 \mu \mathrm{s}$ and pulse off time $25 \mu \mathrm{s}$

\section{Confirmation Test}

The confirmation tests are conducted to check the performance parameters improved. The experimental results are compared using the initial (orthogonal array) and final (predict design) EDM process parameters on HASTELLOY C-276 alloy are shown in the table 7 .

Table 7: Confirmation test result

\begin{tabular}{|c|c|c|c|}
\hline $\begin{array}{c}\text { Performance } \\
\text { measures }\end{array}$ & $\begin{array}{c}\text { Optimum } \\
\text { condition }\end{array}$ & $\begin{array}{c}\text { Optimum } \\
\text { valve }\end{array}$ & Exp value \\
\hline MRR & $\mathrm{A}_{2} \mathrm{~B}_{3} \mathrm{C}_{3} \mathrm{D}_{2}$ & & 37.212 \\
\hline $\mathrm{SR}$ & $\mathrm{A}_{1} \mathrm{~B}_{1} \mathrm{C}_{1} \mathrm{D}_{3}$ & 2.48 & 2.320 \\
\hline
\end{tabular}

\section{Conclusion}

The present research work is carried out to identify the machining performance of MRR and SR. The following conclusions are observed in this research.

- The most important input parameter which was identified is current affecting the MRR and SR. The impact and consequence of pulse on time is greater for SR

- At lower values of discharge current and pulse on time, higher values of pulse off time the optimum condition for surface roughness was identified at A1B1C1D3 having .Loss of heat and time taken for debris particles to remove from the machined zone takes place with increase in pulse off time.

\section{References}

[1] M. Uthayakumar, M. Adam Khan, S. Thirumalai Kumaran, Adam Slota \& Jerzy Zajac (2015), Machinability of Nickel Based Superalloy by Abrasive Water Jet Machining, Materials andManufacturingProcesses,DOI:10.1080/10426914.2015.1103859.

[2] K.H. Ho and S.T. Newman(2003), State of the art electrical discharge machining (EDM), International Journal of Machine Tools \& Manufacture, 43, 1287-1300.

[3] Guo Y., Wu D., Ma G. and Guo D(2014), Trailing heat sink effects on residual stress and distortion of pulsed laser welded Hastelloy C-276 thin sheets. Journal of Materials Processing Technology, 214(12), pp.2891-2899.

[4] Akhter JI, Shaikh MA, Ahmad M, Iqbal M, Shoaib KA, Ahmad W. Effect of aging on the hardness and impact properties of Hastelloy C-276 (2001), Journal of Materials Science Letters.20 (4):333-5.

[5] Ahmad M, Akhter JI, Iqbal M, Akhtar M, Ahmed E, Shaikh MA and Saeed K (2005), Surface modification of Hastelloy C-276 by $\mathrm{SiC}$ addition and electron beam melting. Journal of nuclear materials, 336(1):120-4

[6] Md.karim Baig and N.venkaiah (2014), Parametric optimization of WEDM for HastelloyC276 using GRA method, International Journal of Engineering Development and Research, ISSN: 23219939, Vol.1, Issue 2, pp.1 -7.

[7] P J. Ross, Taguchi techniques for quality engineering. Mc GrawHill: 1998: 24-98.

[8] D C. Design and analysis of experiments. Wiley: 1997: 395- 476.

[9] Phadke Madhav S. Quality engineering using robust design prentice Hall. 1989: 41- 229.

[10] M Kolli and A Kumar (2014),Parametric Optimization of Boron Carbide Powder Added Electrical Discharge Machining of Titanium Alloy. In Applied Mechanics and Materials, 592, pp. 678-683.

[11] M Kolli and A Kumar (2015), Effect of dielectric fluid with surfactant and graphite powder on Electrical Discharge Machining of titanium alloy using Taguchi method, Engineering Science and Technology, an International Journal, 18(4), pp.524-535.

[12] M Kolli and A Kumar (2015), Surfactant and graphite powderassisted electrical discharge machining of titanium alloy, Proceedings of the Institution of Mechanical Engineers, Part B: Journal of Engineering Manufacture, p.0954405415579019.

[13] A.M.Nikalje, A. Kumar and K.S.Srinadh (2013), Influence of parameters and optimization of EDM performance measures 